\title{
The Effect of Seed Size on Phytochemical Composition in Cowpea Lines (Vigna unguiculata (L.) Walp.) from Burkina Faso
}

\author{
Pierre Alexandre Eric Djifaby Sombié1*, Hemayoro Sama², Antoine Barro3 ${ }^{3}$, Adama Hilou², \\ Martin Kiendrébéogo ${ }^{2}$ \\ ${ }^{1}$ Institute of Environment and Agricultural Research, Ouagadougou, Burkina Faso \\ ${ }^{2}$ Laboratory of Biochemistry and Chemistry Applied (LABIOCA), University of Ouagadougou, Ouagadougou, Burkina Faso \\ ${ }^{3}$ University of Dedougou, Dédougou, Burkina Faso \\ Email: *ericsombie@yahoo.fr
}

How to cite this paper: Sombié, P.A.E.D., Sama, H., Barro, A., Hilou, A. and Kiendrébéogo, M. (2021) The Effect of Seed Size on Phytochemical Composition in Cowpea Lines (Vigna unguiculata (L.) Walp.) from Burkina Faso. Agricultural Sciences, 12, 1462-1472. https://doi.org/10.4236/as.2021.1212093

Received: Ocxtober 23, 2021

Accepted: December 18, 2021

Published: December 21, 2021

Copyright $\odot 2021$ by author(s) and Scientific Research Publishing Inc. This work is licensed under the Creative Commons Attribution International License (CC BY 4.0).

http://creativecommons.org/licenses/by/4.0/ (c) (i) Open Access

\begin{abstract}
The study aimed to determine the effect of seeds size (length, width, thickness and 100 seeds-weight) on their phytochemical composition (total phenolics, total flavonoids, total proteins, soluble sugars and starch) of cowpea accessions (Vigna unguiculata (L.) Walp.) grown in Burkina Faso. The genotypes and their descendants had length, width, thickness and 100 seeds weight between $80 \pm 0.7$ to $7.40 \pm 0.46 \mathrm{~cm} ; 6.51 \pm 0.41$ to $5.76 \pm 0.46 \mathrm{~cm} ; 5.15 \pm 0.37$ to $4.22 \pm 0.22 \mathrm{~cm} ; 12.93 \pm 0.09$ to $20.16 \pm 0.39 \mathrm{~g}$ respectively. Total phenol, total flavonoid and starch contents ranged from $585.37 \pm 9.73$ to $1704.71 \pm 4.87$ mg GAE per $100 \mathrm{~g} \mathrm{DW} ; 41.42 \pm 2.03$ to $52.26 \pm 0.75 \mathrm{mg}$ QE per $100 \mathrm{~g} \mathrm{DW}$; $6.45 \% \pm 0.3 \%$ to $46.58 \% \pm 0.12 \%$ respectively. The soluble sugars and total proteins contents were ranged respectively from $149.33 \pm 3.80$ to $432.82 \pm$ $40.81 \mu \mathrm{g} / 100 \mathrm{mg}$, and $20.28 \pm 0.17$ to $27.32 \pm 0.17$ (\%). Seeds size characters had significant and positive correlations with starch content, and significant and negative correlations with total phenolic content. The study of the genetic parameters of phytochemical traits also revealed that they are slightly influenced by the environment. Genetic factors are believed to account for the variation in the observed seed traits, which provides a high potential of studied accessions for breeding programs.
\end{abstract}

\section{Keywords}

Cowpea, Seeds Size, Phytochemistry, Genetic Parameters 


\section{Introduction}

Cowpea (Vigna unguiculata (L.) Walp., a diploid species with $2 n=2 x=22$ chromosomes is an important staple food crop in Africa because of its high protein content and its tolerance for sandy soil and low rainfall [1]. Also known as cowpea, it is a dicotyledonous grain legume that belongs to the Fabaceae family [2]. $91 \%$ of the global production was provided by Africa alone [1]. Cowpea seeds are the major products for consumption, and seed size is an important component of seed yield and also an essential market trait [3]. Seed weight is the most discriminating variable and accounts for $93 \%$ variance in physical properties [4]. Food grains have been subjected since the beginning of agriculture to selection and breeding for size and the most grains consumed today are larger than their wild relative [5]. It is already shown that seed weight influences dispersal ability and seedling establishment, and large seeds also contain enough nourishing substances for germination and have better tolerance to abiotic stresses [6] [7]. It is reported that many genes govern cowpea seed weight (size) by acting mainly additively with small size partially dominant over large [3]. TTG2 (TRANSPARENT TESTA GLABRA2), AP2 (APETALA2), ARF2 (AUXIN RESPONSE FACTOR2)/MNT (MEGAINTEGUMENTA), DA1, KLU (KLUH)/ CYP78A5 (CYTOCHROME P450 78A5) and DA2 are some characterized maternal factors acting in the seed coat to influence seed size [8]. In Arabidopsis and rice, ubiquitin pathway, transcription factors, G-protein signaling, and hormone signaling are involved in maternal control of seed size [7]. Seed size variation is remarkably large among the different cowpea genotypes from Burkina Faso. The relation between seeds size and biochemical composition of cowpea is not well understood. Therefore, the aim of this study was to assess the effect of seed size on phytochemical composition in some cowpea accessions (Vigna unguiculata (L.) Walp.) from Burkina Faso.

\section{Material and Methods}

\subsection{Plant Material}

The seeds of five lines of cowpea were used in this study. The seeds of cowpea varieties were classified into five groups based on the seed size as very small, small, and medium, large and very large. The lines used based on seed size were classified as follows: IT81D-994: very large, Yiisyandé: large, Komcallé: medium, Niizwe: small, Melakh: very small. IT81D-994 line is the parent who transmitted the grain size character, Mélakh the parent with the very smallest seeds and the other Parents were constituted of Yiisyandé, Komcallé and Niizwe lines. Four descendant plants BC2F1 (hybrid heterozygous): [Yiisyandé $\times$ IT81D-994] Yiisyandé; [Niizwe $\times$ IT81D-994] Niizwe; [Mélakh $\times$ IT81D-994] Mélakh; [Komcallé $\times$ IT81D-994] Komcallé and four descendants plants BC2F2 (homozygous) [Yiisyandé $\times$ IT81D-994] Yiisyandé; [Niizwe $\times$ IT81D-994] Niizwe; [Mélakh $\times$ IT81D-994] Mélakh; [Komcallé $\times$ IT81D-994] Komcallé resulting from various 
retro-crossings were also used in this study.

\subsection{Field Experiment}

\subsubsection{Obtaining the Retro-Crossing Plants}

To cross two varieties in cowpeas, one was chosen as the male parent and the other as the female parent. In these cases, a large number of crosses were made to obtain the maximum of grains. The crossing consisted in making an incision of about $2 / 3$ the width of the unhatched button of the plant chosen as female (Yiisyandé, Niizwe, Mélakh, Komcallé); gently detaching the incised outer portion; ablating all the stamens of the flower of the variety chosen as female without bursting them and pollinating the emasculated flower with pollen from the flower of the variety chosen as male (IT81D-994). At maturity, only the pods from a cross were harvested. The pods were then dried, shelled and the seeds packaged in envelopes with the date, type of cross and varieties. The envelopes were then kept in the CREAF-Kamboinsé (INERA) cold room until the experiment was carried out in the Laboratory of Biochemistry and Chemistry Applied (LABIOCA), University Joseph KI-ZERBO, Burkina Faso. The male parent was chosen for the grain size. After the step of creating the F1 individuals, it was proceeded to the creation of the $\mathrm{BC} 1 \mathrm{~F} 1, \mathrm{BC} 2 \mathrm{~F} 1$ individuals using this time the F1 and BC1F1 individuals as female parents and the Yiisyandé, Niizwe, Mélakh, Komcallé varieties as male parents in order to keep the maximum of their characters in the descendants. BC1F1 individuals were then self-fertilized and gave birth to $\mathrm{BC} 2 \mathrm{~F} 2$ individuals who were homozygous. The crosses were made in a greenhouse of Saria (INERA) protected from insects.

\subsubsection{Agro-Morphological Evaluation}

Agro-morphological traits of seeds of different lines and descendants of cowpea were assessed. The studied parameters included the length, width and thickness of seed, and 100 seeds weight were determined. The measurement of length, width and thickness of five groups of twenty (20) seeds each randomly selected were done using an electronic Vernier caliper (precision of $0.01 \mathrm{~mm}$ ) and five groups of hundred seeds weight using an electronic balance (precision $0.001 \mathrm{~g}$ ).

\subsection{Biochemical Parameters}

\subsubsection{Moisture and Ash Content}

The moisture was determined by drying in an electric oven at $110^{\circ} \mathrm{C}$ until a constant weight was obtained. Moisture content was then calculated as per cent water loss. The ash content was determined after calcination in a muffle furnace at $550^{\circ} \mathrm{C}$.

\subsubsection{Soluble Sugars Content}

The seeds of cowpea of different lines of cowpea $(500 \mathrm{mg})$ were homogenized in $5 \mathrm{ml}$ of hot ethanol (80\%). The homogenate was centrifuged after cooling at $4000 \mathrm{rpm}$ for $10 \mathrm{~min}$. The supernatant was used to estimate the soluble sugar 
content of cowpea seeds.

The soluble sugars content of the cowpea seed extracts was determined at 490 using the phenol-sulfuric acid method as described by Dubois et al. [9]. The total sugar content was expressed as $\mu \mathrm{g}$ glucose equivalent/100milligram of seeds dried weight ( $\mu \mathrm{g}$ GE/100mg of seeds DW).

\subsubsection{Total Starch Content}

Total starch content was determined using iodine colorimetric method as described by Jarvis et al. [10]. The total starch content was expressed as g/100g of seeds dried weight.

\subsubsection{Protein Content}

The protein concentration was determined by the Kjeldahl method as described by Philomena et al. [11]. The total $\mathrm{N}_{2}$ was determined and multiplied by the factor 6.25 .

\subsubsection{Total Phenolics and Total Flavonoids Contents}

$500 \mathrm{mg}$ of seeds powder of each cowpea line were extracted with $10 \mathrm{ml}$ of acetone: water $(80: 20 \mathrm{v} / \mathrm{v})$. The mixture was shaken for $24 \mathrm{~h}$ and centrifuged at 4500 rpm for 15 minutes. The supernatant was used for the quantification of total phenolics and total flavonoids contents.

The total phenolics and total flavonoids contents of seeds extracts were determined respectively at $760 \mathrm{~nm}$ and $415 \mathrm{~nm}$ using the methods described by Sombié et al. [12]. The total phenolics were expressed as mg of gallic acid equivalent per 100 gram of seeds dried weight (mg GAE/100g of seeds dried weight) and total flavonoids expressed as mg of quercetin equivalents (QE) per 100 gram of seeds dried weight (mg QE/100g of seeds dried weight).

\subsection{Statistical Analysis}

The results are presented as mean \pm SD for triplicate analysis. Two-way analysis of ANOVA variation followed by Tukey's Significant Difference test was used to compare the results and $\mathrm{P}<0.05$ was considered significant. The Pearson correlation test was used to study the different correlations between the agro- morphological and biochemical parameters.

Genetic parameters were calculated using formula proposed by Falconer and Mackay [13]. The measured variables were processed by analysis of variance to determine the genotype effect. The measured population variables are processed by descriptive statistical analysis, to obtain the means, minimum and maximum extreme values, amplitude and phenotypic variances of the populations. Components of variation are deduced to estimate coefficients of phenotypic (CVP) and genotypic (CVG) variability and the degree of heritability of traits measured by the ratio of phenotypic and genotypic variances to the trait mean:

$$
\operatorname{CVP}(\%)=\frac{100 * \sigma^{2}}{X} ; \quad \operatorname{CVG}=\frac{100 * \sigma^{2}}{X}
$$


CVP: coefficients of phenotypic variation; CVG: coefficient of genotypic variation; $\sigma^{2}$ is either the total phenotypic or genotypic variance deduced from the analysis of variance by equating the mean expectations with the mean squares of the variances; $X$ is the overall mean of the trait.

These same components are estimated, for the variables measured by population, on the basis of the calculation of the variances of the F2, taken as equal to the total phenotypic variance $\left(\sigma^{2} p\right)$, the variance of the parents is taken as equal to the residual variance $\left(\sigma^{2} e\right)$, and the genetic component of this variance which is deduced by difference:

$$
\sigma^{2} G=\sigma^{2} p-\sigma^{2} e
$$

Heritability in the broad sense $\left(h^{2} B S\right)$ is estimated by the ratio of genetic variance to total phenotype variance: $h^{2} B S=\sigma^{2} G / \sigma$.

\section{Results and Discussion}

Table 1 summarizes the effect of varietal difference on agro-morphological traits of cowpea seeds. There were statistical differences in seed length, width, thickness and 100 seeds weight among the genotypes at the $\mathrm{p}<0.05$ level.

The length $(\mathrm{cm})$ of cowpea seeds lines ranged from $7.40 \pm 0.46$ to $9.80 \pm 0.7$ $\mathrm{cm}$. Seeds from the parent IT 81D-994 showed the significantly higher seed length values than the rest of the genotypes. The lowest value of length found was in the parent Melahk genotype, but it was not significant relative to the descendant BC2F2 (Melahk $\times$ [IT 81D-994] Melahk) seeds $(7.45 \pm 0.38 \mathrm{~cm})$.

Cowpea IT 81D-994 $(6.51 \pm 0.41 \mathrm{~cm})$, Yiisyandé $(6.48 \pm 0.34 \mathrm{~cm})$, Niizwé $(6.46 \pm 0.35 \mathrm{~cm})$ and Komcallé $(6.46 \pm 0.35 \mathrm{~cm})$ lines recorded higher mean values for width $(\mathrm{cm})$. The parent melahk $(6.03 \pm 0.43 \mathrm{~cm})$ genotype showed the significant same value for width with all the BC2F2 descendants. The seeds of Yiisyandé genotype $(5.15 \pm 0.37 \mathrm{~cm})$ showed no significantly higher mean value for thickness when compared to those of IT 81D-994 $(5.11 \pm 0.45 \mathrm{~cm})$, Niizwé $(4.87 \pm 0.33 \mathrm{~cm})$ and Komcallé $(4.85 \pm 0.35 \mathrm{~cm})$ genotypes. The descendant

Table 1. Agro-morphological trait of cowpea seeds.

\begin{tabular}{|c|c|c|c|c|c|}
\hline Type of Cross & Cowpea lines & Length $(\mathrm{cm})$ & Width $(\mathrm{cm})$ & Thickness $(\mathrm{cm})$ & 100 seeds weight $(\mathrm{g})$ \\
\hline \multirow{5}{*}{ Parent } & IT 81D-994 & $9.80 \pm 0.7 a$ & $6.51 \pm 0.41 \mathrm{a}$ & $5.11 \pm 0.45 \mathrm{a}$ & $20.16 \pm 0.39 \mathrm{a}$ \\
\hline & Yiisyandé & $9.18 \pm 0.74 b$ & $6.48 \pm 0.34 \mathrm{a}$ & $5.15 \pm 0.37 \mathrm{a}$ & $19.24 \pm 0.23 b$ \\
\hline & Niizwé & $8.72 \pm 0.42 \mathrm{bc}$ & $6.46 \pm 0.35 \mathrm{a}$ & $4.87 \pm 0.33 \mathrm{ab}$ & $14.85 \pm 0.25 \mathrm{~d}$ \\
\hline & Komcallé & $8.88 \pm 0.76 \mathrm{bc}$ & $6.46 \pm 0.35 \mathrm{a}$ & $4.85 \pm 0.35 \mathrm{ab}$ & $18.77 \pm 0.25 b$ \\
\hline & Melahk & $7.40 \pm 0.46 \mathrm{~d}$ & $6.03 \pm 0.43 b$ & $4.46 \pm 0.32 \mathrm{~cd}$ & $13.76 \pm 0.34 \mathrm{e}$ \\
\hline \multirow{4}{*}{$\mathrm{BC} 2 \mathrm{~F} 2$} & Yiisyandé $\times$ [IT 81D-994] Yiisyandé & $8.92 \pm 0.81 \mathrm{bc}$ & $5.76 \pm 0.46 \mathrm{~b}$ & $4.69 \pm 0.47 \mathrm{bc}$ & $17.74 \pm 0.06 \mathrm{c}$ \\
\hline & Niizwé $\times$ [IT 81D-994] Niizwé & $8.33 \pm 0.52 c$ & $5.84 \pm 0.26 \mathrm{~b}$ & $4.38 \pm 0.29 \mathrm{~cd}$ & $15.18 \pm 0.21 \mathrm{~d}$ \\
\hline & Komcallé $\times$ [IT 81D-994] Komcallé & $8.63 \pm 0.55 b c$ & $6.04 \pm 0.30 \mathrm{~b}$ & $4.59 \pm 0.33 \mathrm{bc}$ & $17.10 \pm 0.24 \mathrm{c}$ \\
\hline & Melahk $\times$ [IT 81D-994] Melahk & $7.45 \pm 0.38 \mathrm{~d}$ & $5.87 \pm 0.32 b$ & $4.22 \pm 0.22 \mathrm{~d}$ & $12.93 \pm 0.09 \mathrm{f}$ \\
\hline
\end{tabular}


BC2F2 (Melahk $\times$ [IT 81D-994] Melahk line recorded the weak thickness (4.22 \pm $0.22 \mathrm{~cm}$ ) but not significantly different with those of the parent Melahk (4.46 \pm $0.32 \mathrm{~cm}$ ) and the descendant BC2F2 (Niizwé $\times$ [IT 81D-994] Niizwé $(4.38 \pm 0.29$ $\mathrm{cm})$.

The 100 seeds weight $(\mathrm{g})$ of the different lines varied from $12.93 \pm 0.09$ to $20.16 \pm 0.39 \mathrm{~g}$. The IT $81 \mathrm{D}-994$ genotype showed the highest 100 seeds weight and the descendant (Melahk $\times$ [IT 81D-994] Melahk) showed the weakest 100 seeds weight.

According to Davies and Zibokere [4] cowpea varieties' seed size was divided into four categories based on their 100 seeds weight: Varieties with seeds 10 - 15 $\mathrm{g}$ are described as small, $15.1-20 \mathrm{~g}$ as medium-sized seeds while large seeds have 20.1 - $25.0 \mathrm{~g}$. Seeds weighing over $25 \mathrm{~g}$ are described as very large seeds.

Based on this classification, the parent IT 81D-994 will be classified as variety with large seeds. The parents Yiisyandé and Komcallé, and the descendants BC2F2 (Yiisyandé $\times$ [IT 81D-994] Yiisyandé, BC2F2 Niizwé $\times$ [IT 81D-994] Niizwé and BC2F2 Komcallé $\times$ [IT 81D-994] Komcallé will be classified as genotypes with medium size seeds. Niizwé, melahk and the descendant BC2F2 Melahk $\times$ [IT 81D-994] Melahk are genotypes with small seeds. Any variety with very large seeds was not found in this study.

The variation observed for seeds size in this study might be attributed to crop growth, the development and maturation of seed, and of the inherent genetic differences among different lines [14].

When Table 2 is examined, statistically significant differences $(\mathrm{p}<0.05)$ should be seen between the lines of cowpea in terms of total phenolics, total flavonoids, starch, soluble sugars and total proteins contents.

The seeds of the BC2F2 [Komcallé $\times$ IT81D-994] Komcallé line contained significantly the higher level of total phenolics than all the other lines of $V$. unguiculata reaching $1704.71 \pm 4.87 \mathrm{mg}$ GAE per $100 \mathrm{~g}$ DW. Komcallé line had the

Table 2. Phytochemical compounds content of cowpea lines.

\begin{tabular}{|c|c|c|c|c|c|c|}
\hline $\begin{array}{l}\text { Type of } \\
\text { cross }\end{array}$ & Cowpea lines & $\begin{array}{l}\text { Total Phenolic } \\
(\mathrm{mg} / 100 \mathrm{~g})\end{array}$ & $\begin{array}{l}\text { Total Flavonoids } \\
\quad(\mathrm{mg} / 100 \mathrm{~g})\end{array}$ & Starch (\%) & $\begin{array}{l}\text { Soluble Sugars } \\
(\mu \mathrm{g} / 100 \mathrm{mg})\end{array}$ & $\begin{array}{c}\text { Total Proteins } \\
(\%)\end{array}$ \\
\hline \multirow{5}{*}{ Parent } & IT 81D-994 & $873.17 \pm 4.87 \mathrm{e}$ & $44.09 \pm 1.73 \mathrm{bc}$ & $23.53 \pm 0.09 c$ & $246.72 \pm 23.52 \mathrm{c}$ & $23.71 \pm 0.42 b$ \\
\hline & Yiisyandé & $597.05 \pm 19.38 \mathrm{~g}$ & $52.26 \pm 0.75 \mathrm{a}$ & $24.71 \pm 0.07 b$ & $168.65 \pm 8.67 \mathrm{ef}$ & $23.97 \pm 0.17 b$ \\
\hline & Niizwé & $683.07 \pm 6.37 \mathrm{f}$ & $44.76 \pm 0.85 \mathrm{bc}$ & $17.29 \pm 0.36 \mathrm{e}$ & $174.74 \pm 3.60 \mathrm{ef}$ & $27.32 \pm 0.17 \mathrm{a}$ \\
\hline & Komcallé & $585.37 \pm 9.73 \mathrm{~g}$ & $44.41 \pm 1.63 \mathrm{bc}$ & $46.58 \pm 0.12 \mathrm{a}$ & $338.11 \pm 10.27 b$ & $21.45 \pm 1.68 \mathrm{~cd}$ \\
\hline & Melahk & $992.11 \pm 14.60 \mathrm{~d}$ & $46.16 \pm 3.81 \mathrm{abc}$ & $19.27 \pm 0.73 \mathrm{~d}$ & $149.33 \pm 3.80 \mathrm{f}$ & $20.28 \pm 0.17 \mathrm{~d}$ \\
\hline \multirow{4}{*}{$\mathrm{BC} 2 \mathrm{~F} 2$} & [Yiisyandé × IT81D-994] Yiisyandé & $1235.31 \pm 7.36 \mathrm{c}$ & $49.14 \pm 3.46 \mathrm{ab}$ & $19.34 \pm 0.12 \mathrm{~d}$ & $227.35 \pm 13.12 \mathrm{~cd}$ & $23.80 \pm 0.33 b$ \\
\hline & [Niizwé × IT81D-994] Niizwé & $610.86 \pm 9.73 \mathrm{~g}$ & $41.42 \pm 2.03 \mathrm{c}$ & $12.07 \pm 0.55 \mathrm{~g}$ & $432.82 \pm 40.81 \mathrm{a}$ & $23.80 \pm 0.33 b$ \\
\hline & [Komcallé $\times$ IT81D-994] Komcallé & $1704.71 \pm 4.87 \mathrm{a}$ & $47.34 \pm 1.82 \mathrm{abc}$ & $15.75 \pm 0.18 \mathrm{f}$ & $190.41 \pm 7.69 \mathrm{def}$ & $22.71 \pm 0.08 \mathrm{bc}$ \\
\hline & [Melahk × IT81D-994] Melahk & $1271.42 \pm 20.48 b$ & $49.95 \pm 0.16 \mathrm{ab}$ & $6.45 \pm 0.3 \mathrm{~h}$ & $206.21 \pm 4.98 \mathrm{cde}$ & $25.98 \pm 0.17 \mathrm{a}$ \\
\hline
\end{tabular}


lowest total phenolic content of $585.37 \pm 9.73 \mathrm{mg}$ GAE per $100 \mathrm{~g}$ DW. The highest total flavonoids content was obtained in the Yiisyandé line $(52.26 \pm 0.75 \mathrm{mg}$ $\mathrm{QE} / 100 \mathrm{~g}$ ) and the lowest content was found in the BC2F2 [Niizwé $\times$ IT81D-994] Niizwé line (41.26 $\pm 2.03 \mathrm{mg}$ QE/100g).

The cowpea lines exhibited a wide range of variation in seed starch (\%). The majority of parent genotypes exhibited high starch content. The average content of seeds starch varied from $46.58 \% \pm 0.12 \%$ in Komcallé to $6.45 \% \pm 0.3 \%$ in [Melahk $\times$ IT81D-994] Melahk. Results revealed a higher concentration of soluble sugars in [Niizwé $\times$ IT81D-994] Niizwé, while Melahk exhibited the lowest amount of soluble sugars accumulation respectively of $432.82 \pm 40.81$ and 149.33 $\pm 3.80 \mu \mathrm{g} / 100 \mathrm{mg}$. Significant differentiation was observed in total proteins concentration within the studied cowpea lines. The cowpea lines had a wide range of variation in total proteins ranging from $27.32 \pm 0.17$ to $20.28 \pm 0.17$ (\%). The varieties with the greatest total proteins were Niizwé $(27.32 \% \pm 0.17 \%)$ and $[\mathrm{Me}-$ lahk $\times$ IT $81 \mathrm{D}-994]$ Melahk $(25.98 \% \pm 0.17 \%)$ and those with the lowest was Melahk $(20.28 \% \pm 0.17 \%)$.

\subsection{Genetic Parameters}

Table 3 summarizes the genetic parameters of the phytochemical parameters of the seeds of the different varieties. The results showed variations in the phenotypic and genotypic coefficients of variation according to the studied parameters. In general, and for all parameters studied, the phenotypic coefficients of variation were slightly higher compared to the genotypic ones. Furthermore, only water and starch content showed low genotypic and phenotypic coefficients $(\leq 10 \%)$. The other parameters showed high coefficients $(\geq 20 \%)$. The existence of significant differences among the genotypes for all the seeds studied traits, indicates the presence of considerable genetic variability among the different varieties. This variability in seeds traits could offer many opportunities to improve different quantitative and qualitative traits through breeding [15] [16].

Table 3. Genetic parameters of the phytochemical compounds of the seeds.

\begin{tabular}{cccccccccc}
\hline Traits & $\sigma^{2} g$ & $\sigma^{2} p$ & $\sigma^{2} e$ & Mean & GCV (\%) & PCV (\%) & Hbs & GA (\%) & GAM \\
\hline Water content & 0.053 & 0.052 & 0.001 & 11.362 & 0.005 & 0.068 & 0.994 & 0.228 & 2.007 \\
Ash & 0.031 & 0.031 & 0.000 & 3.369 & 0.096 & 0.310 & 0.989 & 0.174 & 5.169 \\
Total flavonoids & 11.473 & 9.960 & 1.513 & 46.614 & 0.496 & 0.704 & 0.868 & 2.940 & 6.308 \\
Total phenolics & 150.721 & 49.480 & 101.241 & 950.343 & 0.398 & 0.631 & 0.328 & 4.030 & 0.424 \\
Starch & 12.973 & 10.299 & 2.674 & 20.555 & 0.794 & 0.891 & 0.794 & 2.860 & 13.911 \\
Total sugar & 85.135 & 75.199 & 9.936 & 237.149 & 0.599 & 0.774 & 0.883 & 8.150 & 3.437 \\
Proteins & 4.510 & 4.387 & 0.123 & 23.667 & 0.437 & 0.661 & 0.973 & 2.066 & 8.729 \\
100 seeds weight & 6.561 & 6.540 & 0.021 & 16.636 & 0.628 & 0.792 & 0.997 & 2.553 & 15.349 \\
\hline
\end{tabular}

$\sigma^{2} g=$ Genotypic variance, $\sigma^{2} p=$ Phenotypic variance and $\sigma^{2} e=$ Environmental variance, Hbs = Heritability broad sense, GCV $=$ Genotypic coefficient of variation, PCV = Phenotypic coefficient of variation, GA = Genetic advance, GAM = Genetic advance as percent of mean. 
The higher phenotypic than genotypic coefficients of variation would indicate that the phenotypic variation of the observed traits was less influenced by the environment. In addition, the high values for the high phenotypic and genotypic coefficients of variation (20\%) suggest that selection on the basis of the relevant traits would be effective, as there is a good correlation between measured phenotypic and genotypic expression [17]. Indeed, for Admas and Tesfaye [16] the coefficients of phenotypic (CVP) and genotypic (CVG) variability are classified as high (above 20\%), medium (between 10\% and 20\%) and low (below 10\%). In the case of our study, apart from moisture content and total ash, which have low genotypic coefficients, the other traits (coefficients above 20\%) would have good potential for varietal improvement programmes. Similar results were reported by Bartaula et al and, Admas and Tesfaye [15] [17].

All the studied parameters excluding the phenolic compounds showed high values of heritability in the broad sense $(\geq 60 \%)$. Genetic advance as a percent of mean showed values ranging from $2 \%$ to $15.349 \%$. Thus, genetic advances as a percent of mean are low for water, total ash, total flavonoids, total polyphenols, total sugars and total proteins which showed values below $10 \%$. Only starch and 100 -seed weight showed high genetic advance. Our studied traits in general show high broad heritability coupled with low genetic advance as a percent mean. Such results suggest expression of the trait is under the control of non-additive type of gene action, and its response to selection would be poor. Indeed, according to Bartaula et al. [15], traits which expressed high heritability coupled with high genetic advance indicate the preponderance of additive gene action in controlling the traits. Hence direct selection of such characters would be effective in improving the yield. However, traits with high heritability coupled with low genetic advance, suggest expression of the trait is under the control of non-additive type of gene action, and its response to selection would be poor. Those with lower heritability as well as genetic advance suggesting the trait governance by non-additive gene action and direct selection would not be effective for the trait [15].

\subsection{Phytochemical Compounds Contribution to the Seeds Size in Cowpea Lines (Vigna unguiculata (L.) Walp.) from Burkina Faso}

Pearson correlation matrix between the phytochemical and seeds size in cowpea lines was performed and presented in Table 4. Significant relationship between starch content and seeds size (weight, length, width and thickness) were observed. There were strong positive and significant correlations between the starch content and the weight $(\mathrm{r}=0.639, \mathrm{p}<0.05)$, the starch content and the length $(r=0.467, p<0.05)$, the starch content and the width $(r=0.611, p<0.05)$, the starch content and the thickness $(r=0.585, p<0.05)$. Furthermore, negative correlations were also found between the total phenolic content and seeds size. In contrast, weak correlations were observed between the total flavonoids and 
Table 4. Pearson correlation coefficient.

\begin{tabular}{cccccc}
\hline & Total flavonoids & Total phenolics & Starch & Sugars & Proteins \\
\hline 100 seeds Weight & 0.057 & -0.206 & 0.639 & 0.123 & -0.220 \\
Length & -0.081 & -0.267 & 0.467 & 0.134 & 0.106 \\
Width & -0.074 & -0.540 & 0.611 & -0.171 & 0.067 \\
Thickness & 0.105 & -0.434 & 0.585 & -0.183 & 0.041 \\
\hline
\end{tabular}

seeds size, between sugars content and seeds size and between proteins content and seeds size. Size and chemical composition are important aspects of the quality of seed [18].

This study showed that the seed weight of cowpea variety could be a useful criterion for determining suitability for a particular end-use application. Varieties with large seeds would be preferred for high starch content, however seeds with small width would be preferred for high total phenolic content.

\section{Conclusion}

In this study, the cowpea accessions exhibited variations of phytochemical constituents according to the size of their seeds. The larger size of seeds from the cowpea accession was accompanied by higher content of starch; however the seeds with small size achieved the highest total phenolic content. The study showed that the size of the seeds has no influence on their soluble sugars, total proteins and total flavonoids contents. It is suggested that the results reflect the influence of inheritance on the seeds size and phytochemical composition of cowpea.

\section{Acknowledgements}

The research work has been done with the financial support of International Centre for Genetic Engineering and Biotechnology (CRP-ICGEB BFA 20-01) and The World Academy of Sciences (TWAS NO 20-155 RG/BIO/AF/AC_I-FR 3240314143) individual Fellowship Grant granted to the first author

\section{Conflicts of Interest}

The authors declare no conflicts of interest regarding the publication of this paper.

\section{References}

[1] Doumbia, I.Z., Akromah, R. and Asibuo, J.Y. (2013) Comparative Study of Cowpea Germplasms Diversity from Ghana and Mali Using Morphological Characteristics. Journal of Plant Breeding and Genetics, 1, 139-147.

[2] Menssen, M., Linde, M., Otunga, Omondi, E., Abukutsa-Onyango, M., Dinssa, F.F. and Winkelmann, T. (2017) Genetic and Morphological Diversity of Cowpea ( Vigna unguiculata (L.) Walp.) Entries from East Africa. Scientia Horticulturae, 226, 
268-276. https://doi.org/10.1016/j.scienta.2017.08.003

[3] Egbadzor, K.F., Dadoza, M., Danquah, E.Y., Yeboah, M., Offei, S.K.A. and Ofori, K. (2013) Genetic Control of Seed Size in Cowpea (Vigna unguiculata (L.) Walp). International Journal of Agriculture Sciences, 5, 367-371.

[4] Davies, R.M. and Zibokere, D.S. (2011) Effects of Moisture Content on Some Physical and Mechanical Properties of Three Varieties of Cowpea (Vigna unguiculata (L) Walp). Agricultural Engineering International: CIGR Journal, 13, 1-8.

[5] Sundaresan, V. ((2005) Control of Seed Size in Plants. Proceedings of the National Academy of Sciences of the United States of America, 102, 17887-17888. https://doi.org/10.1073/pnas.0509021102

[6] Kyari, B.A., Mohammed, F.K., Apagu, B. and Waziri, M.S. (2017) The Relationship between Seed Weight, Nutrient Composition and Germinating Seeds of Five Tree Species of the Lake Chad Basin Area of Nigeria. Donnish Journal of Agricultural Research, 4, 1-4.

[7] Li, N. and Li, Y. (2015) Maternal Control of Seed Size in Plants. Journal of Experimental Botany, 66, 1087-1097. https://doi.org/10.1093/jxb/eru549

[8] Doughty, J., Aljabri, M. and Scott, R.J. (2014) Flavonoids and the Regulation of Seed Size in Arabidopsis. Biochemical Society Transactions, 42, 364-369. https://doi.org/10.1042/BST20140040

[9] Dubois, M., Gilles, K.A., Hamilton, J.K., Rebers, P.A. and Fred, S. (1956) Colorimetric Method for Determination of Sugars and Related Substances. Analytical Chemistry, 28, 350-356. https://doi.org/10.1021/ac60111a017

[10] Jarvis, C.E. and Walker, J.R.L. (1993) Simultaneous, Rapid, Spectrophotometric Determination of Total Starch, Amylose and Amylopectin. Journal of the Science of Food and Agriculture, 63, 53-57. https://doi.org/10.1002/jsfa.2740630109

[11] Philomena, N.O., Chinyere, V.I., Patience, C.E., Bibian, O.A. and Finian, C.I. (2020) Determination of Phytochemical and Proximate Constituents of Two Varieties of Hibiscus sabdariffa. Asian Journal of Research in Botany, 3, 1-8.

[12] Sombie, P., Compaore, M., Coulibal,y A.Y., Ouedraogo, J.T., Tignegre, J.S. and Kiendrebeogo, M. (2018) Antioxidant and Phytochemical Studies of 31 Cowpeas (Vigna unguiculata (L. Walp.)) Genotypes from Burkina. Foods, 7, Article No. 143. https://doi.org/10.3390/foods7090143

[13] Falconer, D.S. and Mackay, T.F.C. (1996) Introduction to Quantitative Genetic. Logman Group, New York.

[14] Gerrano, A.S., Jansen, V.R.W.S. and Adebola, P.O. (2017) Preliminary Evaluation of Seed and Germination Traits in Cowpea (Vigna unguiculata) Genotypes. South African Journal of Plant and Soil, 34, 399-402. https://doi.org/10.1080/02571862.2017.1317849

[15] Bartaula, S., Panthi, U., Timilsena, K., Acharya, S.S. and Shrestha, J. (2019) Variability, Heritability and Genetic Advance of Maize (Zea mays L.) Genotypes. Research in Agriculture, Livestock and Fisheries, 6, 163-169.

[16] Admas, A.A. and Tesfaye, M.D. (2017) Genetic Variability and Character Association of Some Local Wheat Varieties (Triticum Species) Using Agromorphological Traits Grown in South Gondar Zone, Ethiopia. African Journal of Biotechnology, 16, 2100-2105. https://doi.org/10.5897/AJB2015.15018

[17] Oulmi, A., Semcheddine, N. Fellahi, Z.E.A., Salmi, M., Laala, Z. and Rabti, A. (2016) Variabilité génétique, héritabilité et corrélations entre les caractères phéno-morpho-physiologiques et agronomiques des populations F2 de blé dur 
(Triticum durum Desf.). International Journal of Innovation and Applied Studies, 17, 1275-1285.

[18] Fenner, M. (1992) Environmental Influences on Seed Size and Composition. Horticultural Reviews, 13, 183-213. https://doi.org/10.1002/9780470650509.ch5 